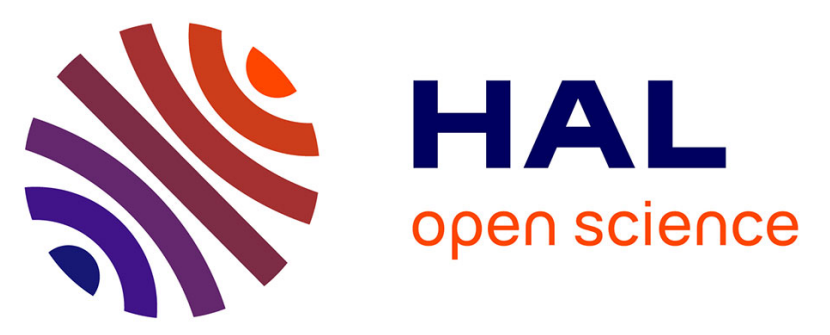

\title{
Large-Core Hollow-Core Antiresonant Fiber with Low-Loss and Truly Single-Mode Guidance for N-IR Wavelengths
}

Laurent Provino, Adil Haboucha, Mélanie Havranek, Achille Monteville, David Landais, Olivier Le Goffic, Xavier Insou, Margaux Barbier, Thierry

Chartier, Monique Thual, et al.

\section{To cite this version:}

Laurent Provino, Adil Haboucha, Mélanie Havranek, Achille Monteville, David Landais, et al.. LargeCore Hollow-Core Antiresonant Fiber with Low-Loss and Truly Single-Mode Guidance for N-IR Wavelengths. Advanced Solid State Lasers Conference (ASSL 2018), Nov 2018, Boston, MA, United States. pp.ATh1A.6, 10.1364/ASSL.2018.ATh1A.6 . hal-01926819

\section{HAL Id: hal-01926819 https://hal.science/hal-01926819}

Submitted on 19 Nov 2018

HAL is a multi-disciplinary open access archive for the deposit and dissemination of scientific research documents, whether they are published or not. The documents may come from teaching and research institutions in France or abroad, or from public or private research centers.
L'archive ouverte pluridisciplinaire HAL, est destinée au dépôt et à la diffusion de documents scientifiques de niveau recherche, publiés ou non, émanant des établissements d'enseignement et de recherche français ou étrangers, des laboratoires publics ou privés. 


\title{
Large-Core Hollow-Core Antiresonant Fiber with Low-Loss and Truly Single-Mode Guidance for N-IR Wavelengths
}

\author{
Laurent Provino $^{{ }^{*}}$, Adil Haboucha ${ }^{1}$, Mélanie Havranek ${ }^{1}$, Achille Monteville ${ }^{1}$, David Landais ${ }^{1}$, Olivier Le \\ Goffic $^{1}$, Xavier Insou ${ }^{2}$, Margaux Barbier ${ }^{2}$, Thierry Chartier ${ }^{2}$, Monique Thual ${ }^{2}$, and Thierry Taunay ${ }^{1}$ \\ 1 PERFOS, Research Technology Organization of Photonics Bretagne, 4 rue Louis de Broglie, 22300 Lannion, France \\ 2 Univ Rennes, CNRS, Institut FOTON - UMR 6082, F-22305 Lannion, France \\ *lprovino@photonics-bretagne.com
}

\begin{abstract}
We report on the modeling and characterization of a truly single-mode hollow-core antiresonant fiber with a transmission band covering part of the near-infrared spectral region. Measured losses are $0.075 \mathrm{~dB} / \mathrm{m}$ and $0.052 \mathrm{~dB} / \mathrm{m}$ at $1.55 \mu \mathrm{m}$ and $2.0 \mu \mathrm{m}$ respectively.

OCIS codes: (060.2280) Fiber design and fabrication; (060.2400) Fiber properties; (060.2430) Fiber, single-mode
\end{abstract}

\section{Introduction}

In recent years, hollow-core antiresonant fibers (HC-ARFs) comprising a single ring of glass capillaries have attracted much attention due to their low transmission loss, broad guidance bands and weak power overlap between the core mode and the silica cladding. The leakage loss of this fiber type is inversely proportional to the fourth power of core diameter $D$ [1], so lower losses are much easier to achieve at larger $D$ values. For large core diameters, the HC-ARFs are however multimode and therefore not ideal for applications where high modal purity is required, for example in high-power pulse delivery or in gas cells. Optimal suppression of higher-order modes (HOMs) in HC-ARFs was numerically studied, and can be achieved when the inner capillary-to-core diameter ratio is around 0.68 [2]. In this paper, we report the development of truly single-mode HC-ARF with six non-touching antiresonant capillaries for low-loss transmission in the near-infrared (N-IR) spectral domain.

\section{Design and modeling of HC-ARF}

Schematic cross-section of the studied HC-ARF is shown in Fig. 1(a) (inset). Considering the fact that the transmission band positions only depend on the wall thickness $t$ of the capillaries [1,3], the value of $t$ was chosen equal to $490 \mathrm{~nm}$, thus setting the first antiresonant transmission window in the N-IR regime. Note that the first transmission window is the one that allows the widest transmission in all sort of hollow-core fibers [3].
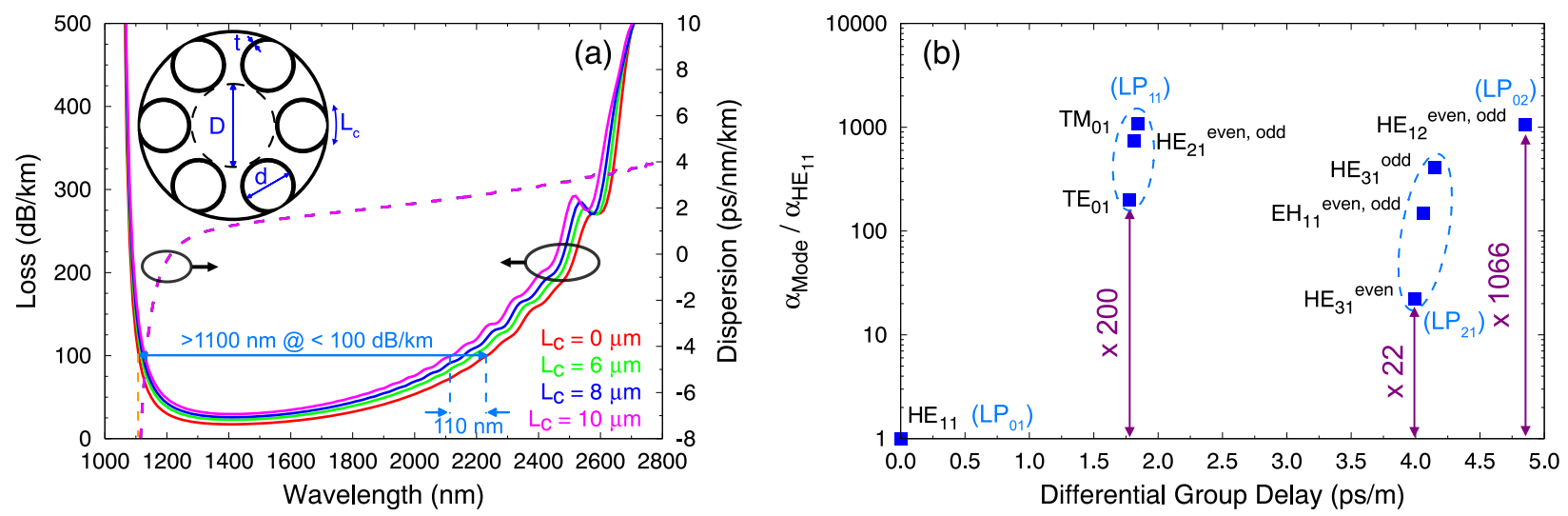

Fig. 1: (a) Simulated loss (solid curves) and chromatic dispersion (dashed curves) for four different values of parameter $L_{c}$. Inset: Sketch of the HC-ARF cross-section, with its key parameters. Glass is marked in black and the hollow regions in white. (b) Simulated differential loss of the first twelve modes positioned relative to their differential group delay calculated with respect to the fundamental mode group index at $1.55 \mu \mathrm{m}$.

The core diameter $D$ and inner diameter $d$ of the capillaries were respectively set at $43 \mu \mathrm{m}$ and $30 \mu \mathrm{m}$, for all numerical simulations with COMSOL. In order to take into account the contact points between the capillaries and the jacketing tube, we introduced in our simulations the parameter $L_{c}$, which defines the contact length of a capillary with the inner sheath. The confinement loss and chromatic dispersion for the fundamental mode of a straight HCARF were simulated for $L_{c}$ values ranging from 0 to $10 \mu \mathrm{m}$. All curves are plotted in Fig. 1(a). The results show a significant influence of the contact length on the transmission performances. For $L_{c}=10 \mu \mathrm{m}$, the fiber transmission bandwidth decreases by $\sim 10 \%$, with losses of less than $100 \mathrm{~dB} / \mathrm{km}$. On the other hand, the chromatic dispersion is not affected with $L_{c}$ variations. In Fig. 1(b), the differential losses with respect to fundamental mode of the first ten HOMs are depicted at the wavelength of $1550 \mathrm{~nm}$. The simulations predict losses at least 200 times higher for the 
first four modes. These high loss values are due to strong resonant coupling between these higher-order core modes and the fundamental air-capillary mode [2]. However, the $\mathrm{HE}_{31}$ mode shows relatively lower loss. But in experiments, this particular HOM is less likely to be excited (the group index difference is about two times higher than for the $\mathrm{TE}_{01}$ mode). The mode field diameter of the fundamental mode does not change significantly across full octave transmission band and has an average value of $34 \mu \mathrm{m}$.

\section{Fiber fabrication and characterization}

Fig. 2(a) (inset) shows the scanning electron microscope (SEM) picture of the HC-ARF, fabricated by the stack-anddraw technique. The fiber is formed of F300 fused silica. Special care was taken during the stages of capillary assemblies and fiber drawing, to limit the contact point width. The fiber diameter is $225 \mu \mathrm{m}$ and the core diameter, defined by the diameter of inscribed circle fitting to the core region, is about $41 \mu \mathrm{m}$. The average values of the capillary wall thicknesses and their contact length are estimated at $480 \mathrm{~nm}$ and $7 \mu \mathrm{m}$, respectively. The loss measurements were measured by cutback method employing a supercontinuum source, and two optical spectrum analyzers (AQ6374 \& AQ6376) to cover the full fiber bandwidth. In order to minimize bend loss effects, the HCARF was rewound on a $45-\mathrm{cm}$ diameter coil. The minimum measured loss was $\sim 25 \mathrm{~dB} / \mathrm{km}$ around $1.65 \mu \mathrm{m}$. Chromatic dispersion was also measured using an experimental setup based on white-light Michelson interferometer. The $1.5 \mathrm{-m}$ long fiber was coiled on $38-\mathrm{cm}$ diameter loop. Irrespectively of wavelength, no overmodulation due to intermodal coupling could be observed in the interferometric spectrum. The results are presented in Fig. 2(a), and show that the dispersion values remain very low $(<3 \mathrm{ps} / \mathrm{nm} / \mathrm{km})$ across the whole transmission window. The single-mode guidance is further confirmed by $\mathrm{S}^{2}$ measurements (see Fig. 2(b)) showing the absence of HOMs after $3 \mathrm{~m}$ of fiber.
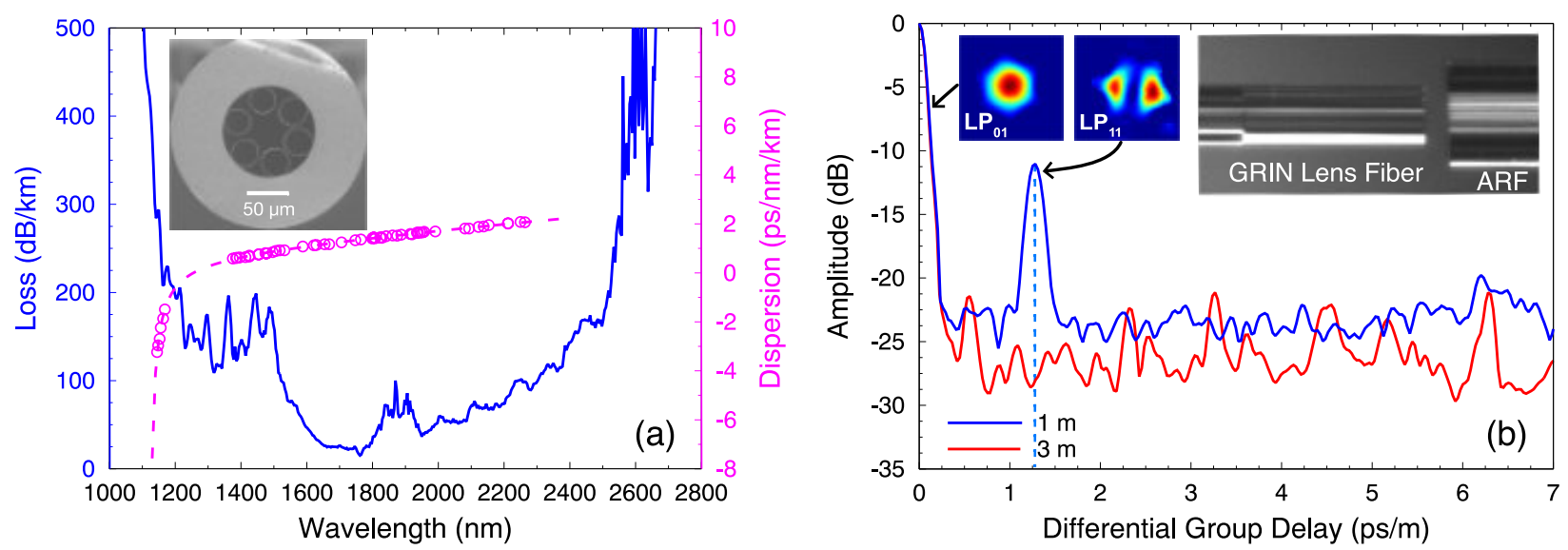

Fig. 2: (a) Measured loss (blue curve) and chromatic dispersion (purple dots) of the HC-ARF. The purple dashed curve represents the fit to experimental dispersion. Inset: SEM picture of HC-ARF in the experiment. (b) $\mathrm{S}^{2}$ measurement of the fiber, indicating the HOM content after 1 $\mathrm{m}$ (blue curve) and a single-mode guidance after $3 \mathrm{~m}$ (red curve). The launching laser source is carried out using a GRIN lens fiber, with a $32 \mu \mathrm{m}$ MFD at $1550 \mathrm{~nm}$ (inset: microlens injection image).

\section{Conclusion and outlook}

In summary, we have designed and fabricated a large core HC-ARF with low-loss transmission band covering part of N-IR spectral region. Minimum loss of $25 \mathrm{~dB} / \mathrm{km}$ has been measured at $1.65 \mu \mathrm{m} .75 \mathrm{~dB} / \mathrm{km}$ average loss at 1.55 $\mu \mathrm{m}$ and $52 \mathrm{~dB} / \mathrm{km}$ at $2.0 \mu \mathrm{m}$ have also been measured. The fiber is also able to guide a unique fundamental mode after only a few meters and provides an alternative route to perform several applications in the N-IR. As an example, one application could be the heterodyne detection for precision measurements like the coherent LIDAR. This fiber is also an ideal candidate for routing high power, short-pulses or ultra-coherent signals, which can provide an alternative to overcome complexity, and the high cost of the current systems.

Funding: This work is supported in part by the "Région Bretagne" and the "Fonds Européen de Développement Economique des Régions".

[1] L. Vincentti, "Empirical formulas for calculating loss in hollow core tube lattice fibers," Optics Express 24, 10313-10325 (2016).

[2] P. Uebel et al., "Broadband robustly single-mode hollow-core PCF by resonant filtering of higher-order modes," Optics Letters 41, 1961-1964 (2016).

[3] F. Poletti, "Nested antiresonant nodeless hollow core fiber," Optics Express 22, 23807-23828 (2014). 